\title{
Context modulates outcome of perinatal glucocorticoid action in the brain
}

\section{E. Ronald de Kloet ${ }^{1,2}{ }^{*}$, Sanne E. F. Claessens ${ }^{1}$ and Jiska Kentrop ${ }^{1}$}

' Department of Medical Pharmacology, Leiden University Medical Center, Leiden University, Leiden, Netherlands

2 Department of Endocrinology and Metabolism, Leiden University Medical Center, Leiden, Netherlands

\section{Edited by:}

Nikolaos P. Daskalakis, Icahn School of Medicine at Mount Sinai, USA

Reviewed by:

Gábor B. Makara, Hungarian Academy of Sciences, Hungary

Nuno Sousa, University of Minho,

Portugal

${ }^{*}$ Correspondence:

E. Ronald de Kloet, Department of Endocrinology and Metabolism, Division of Medical Pharmacology, LACDR, Leiden University Medical Center, Leiden University, PO Box 9503, Leiden 2300 RA, Netherlands e-mail: e.kloet@lacdr.leidenuniv.nl; erdekloet@gmail.com
Prematurely born infants may be at risk, because of inadequate maturation of tissues. If there are signs of preterm birth, it has become common practice therefore to treat either antenatally the mother or postnatally the infant with glucocorticoids to accelerate tissue development, particularly of the lung. However, this life-saving early glucocorticoid treatment was found to increase the risk of adverse outcome in later life. In one animal study, the authors reported a $25 \%$ shorter lifespan of rats treated as newborns with the synthetic glucocorticoid dexamethasone, but so far this finding has not been replicated. After a brief clinical introduction, we discuss studies in rodents designed to examine how perinatal glucocorticoid action affects the developing brain. It appears that the perinatal action of the glucocorticoid depends on the context and the timing as well as the type of administered steroid. The type of steroid is important because the endogenous glucocorticoids cortisol and corticosterone bind to two distinct receptor populations, i.e., mineralocorticoid and glucocorticoid receptors (GR), while synthetic glucocorticoids predominantly bind to the GR. In addition, if given antenatally hydrocortisone is inactivated in the placenta by $11 \beta-H S D$ type 2 , and dexamethasone is not. With respect to timing, the outcome of glucocorticoid effects is different in early vs. late phases of brain development. The context refers to the environmental input that can affect the susceptibility to glucocorticoid action in the newborn rodent brain; early handling of pups and maternal care obliterate effects of post-natal dexamethasone treatment. Context also refers to coping with environmental conditions in later life, for which the individual may have been programed epigenetically by early-life experience. This knowledge of determinants affecting the outcome of perinatal glucocorticoid exposure may have clinical implications for the treatment of prematurely born infants.

Keywords: preterm birth, stress, glucocorticoids, antenatal, post-natal, human, rodent, brain

\section{INTRODUCTION}

The endogenous glucocorticoids cortisol and corticosterone promote the development of various tissues and organ systems during development. However, in prematurely born infants this effect of the steroids on maturation is abrogated resulting in a lifethreatening situation. Therefore, it has become common practice to administer synthetic glucocorticoids such as dexamethasone to accelerate maturation, particularly of lung tissue $(1,2)$. If given antenatally to the mother the mortality of the prematurely born infant is decreased. While the infants obviously benefit from perinatal glucocorticoids, the treatment reportedly can have negative implications for later life outcome, particularly with respect to dexamethasone or its analogs (3-5). This health risk at adulthood includes impaired cardiovascular and immune functions as well as deficits in motor and cognitive performance, altered emotional reactivity, and neuroendocrine regulations.

In this contribution, data from animal and human studies with respect to the perinatal (antenatal and post-natal) action of glucocorticoids are presented. The action of the naturally occurring glucocorticoids is mediated by mineralocorticoid receptors (NR3C2,
MR) and glucocorticoid receptors (NR3C1, GR) $(6,7)$. These glucocorticoids, cortisol, and corticosterone (the latter steroid only in rodents), bind to MR and GR with an order of magnitude difference in binding affinity (6). This implies that corticosterone and cortisol bind to the brain MR with high affinity resulting in substantial occupation even during the very low circulating hormone levels that are typically observed during the circadian trough and in rodents during the early post-natal stress-hyporesponsiveperiod (SHRP). These same steroids bind to GR only in adequate amounts when in adult animals their concentration has increased after stress and at the circadian peak. The membrane variants of MR and GR also display a lower affinity suggesting that their rapid effects preferably occur only at rising and high steroid concentrations during stressful situations and circadian peaks (8). No data exist on the role of these membrane variants during development. The synthetic glucocorticoids preferentially bind to GR, usually with high affinity (9).

We first review the human studies on antenatal activity of the hypothalamic-pituitary-adrenal (HPA)-axis, development of corticosteroid receptors and the effect of antenatal glucocorticoid 
treatment. Then, after an overview of antenatal rodent data, we will discuss the action of dexamethasone during the first post-natal days (pnds) of the newborn rodent, since this resembles most the antenatal treatment protocol in the human. Most animal studies have been performed with male animals; if females are used this is indicated. This contribution is concluded with a translational perspective that may be helpful in the clinical management of perinatal glucocorticoid treatment.

\section{HUMAN STUDIES}

\section{ANTENATAL HPA-AXIS DEVELOPMENT}

During pregnancy, the activity of the maternal HPA-axis gradually increases over time toward a state of hypercortisolism that is caused by the steadily increasing production of corticotropinreleasing hormone $(\mathrm{CRH})$ in the placenta and fetal membranes (10-12)). Fetal levels of CRH, adrenocorticotropic hormone (ACTH), and cortisol also rise, but not as much as the maternal values (13). Most of the cortisol present in amniotic fluid has a maternal origin and has successfully traversed the placenta. However, this accounts for only $10-20 \%$ of maternal cortisol because the remaining $80-90 \%$ is converted to inactive cortisone by the enzyme $11 \beta$-hydroxysteroid dehydrogenase type $2(11 \beta$-HSD2) to protect the fetus from excess glucocorticoid exposure $(14,15)$. During the third trimester, fetal $11 \beta$-HSD2 levels fall and the fetus is exposed to high levels of CRH and endogenous cortisol (16). In this period, cortisol is able to exert its positive influence on the maturation of several organ systems, in preparation of survival after birth $(17,18)$.

\section{ANTENATAL MR AND GR EXPRESSION}

Very limited information is available on human MR and GR expression patterns during gestation. Condon and colleagues reported minimal expression of $\mathrm{MR}$ and GR in peripheral tissues during gestational week 6 , which becomes detectable from gestational weeks 8-16, with in general higher GR compared to MR expression (19). Noorlander et al. (20) studied MR and GR mRNA expression in the hippocampus from gestational week 2434. They reported that both MR and GR mRNA are present during this period, with higher MR compared to GR mRNA levels and little change in expression levels over time (20). However, humans are in part altricial species and antenatal MR and GR expression appear to follow a pattern similar to that in guinea pigs and sheep rather than mice and rats. When comparing rodent brain development to human brain development, the last days of rat gestation (day 22-23) resemble human fetal brain development in week 16-17 regarding relative aspects of neurogenesis, neuron size, and number $(21,22)$.

\section{ANTENATAL GLUCOCORTICOIDS IN THE CLINIC}

In 1972, Liggins and Howie were the first to demonstrate the beneficial effects of antenatal synthetic glucocorticoid treatment in the prevention of respiratory distress syndrome of premature infants (23). It is now known that treatment with the synthetic glucocorticoids dexamethasone and betamethasone accelerates the maturation process of several organ systems (e.g., lungs, heart, and kidneys) and antenatal synthetic glucocorticoid has become the standard treatment for women at risk of preterm delivery (1).
In short-term, antenatal synthetic glucocorticoids reduce neonatal death, incidence of respiratory distress syndrome, cerebroventricular hemorrhage, necrotizing enterocolitis, respiratory support, intensive care admissions, and systemic infections in the first $48 \mathrm{~h}$ of life (2).

There is not much information on the long-term consequences of antenatal synthetic glucocorticoid treatment in humans. Roberts and Dalziel reported in a 2006 Cochrane systematic review, four follow-up studies into childhood and two into adulthood on the effect of a single course of antenatal glucocorticoid treatment (2). No psychological differences were found between antenatal glucocorticoid treatment and placebo for both children and adults. Another Cochrane review failed to show any long-term (adverse) effects of either single or repeated doses of antenatal betamethasone (24).

Despite this positive news on the clinical outcome of perinatal synthetic glucocorticoid treatment in the short-term, there are concerns about the potential negative long-term effects of antenatal overexposure. This is because of data from animal experiments with these synthetic glucocorticoids or derived from endogenous glucocorticoid action during stress (see below). Epidemiological studies have shown an association between high maternal stress, nutritional factors, or infections during pregnancy, which suggested an association of perinatal overexposure to endogenous glucocorticoid with mental disorders in later life. These include retrospective studies in man, such as those involving children born from Dutch mothers that were pregnant during the Dutch "Hunger winter" of 1944-1945. The adults exposed as fetus to these major stressors showed a higher incidence of schizophrenia (25), affective disorder (26), and addiction (27) as well as metabolic disorders (28). Furthermore, depression was associated with maternal influenza infection (29) and autism with mothers suffering from family problems (30). One review focused on animal models derived from epidemiological studies to examine the antenatal influence of maternal stress and nutritional status (31). In a meta-analysis of 60 human and 43 animal studies Beydoun and Saftlas (32) concluded independent effects of antenatal and postnatal outcomes. A vast literature is emerging on the outcome of early post-natal adversity and abuse $(33,34)$. Attempts are under way to ameliorate outcome using micronutrient supplements (35).

However, the consequences of treatment with the synthetic glucocorticoids betamethasone and dexamethasone cannot be directly compared to the impact of exposure to the endogenous glucocorticoids cortisol and corticosterone. First, the synthetic glucocorticoids are poor substrates for $11 \beta$-HSD2 and can pass the placental barrier more readily than endogenous glucocorticoids $(36,37)$. Second, the synthetic glucocorticoids bind the GR with higher affinity than endogenous glucocorticoids (9). Third, the synthetic glucocorticoids are GR-specific rather than MR-specific, while cortisol and corticosterone bind with a 10-fold higher affinity to MR compared to GR (6). And fourth, in the guinea pig MR and GR both are involved in the induction of multidrug resistance P-glycoprotein (P-gp) in the fetal blood-brain-barrier in response to endogenous cortisol, aldosterone, and dexamethasone (38).This finding suggests that upon repeated exposure to dexamethasone access of the synthetic steroid itself may be hampered, because the steroid is a substrate for the transporter (39-41). Regardless, the 
overall picture clearly indicates that glucocorticoid overexposure has long-term consequences and the question is therefore rather how these effects occur.

\section{ANIMAL STUDIES \\ ANTENATAL MR AND GR EXPRESSION}

The programing effects of glucocorticoids during fetal brain development depend on the expression of MR and GR, which are time, location, and species specific. A distinction can be made between altricial and precocial species. Rats and mice are altricial species, which are relatively underdeveloped when born, with critical brain development occurring ante- and postnatally. In precocial species such as guinea pigs and sheep critical brain development occurs mostly antenatal. Primates including humans are considered a mixture of altricial and precocial: in aspects of body development they may be considered precocial, but behaviorally they are altricial.

In rats, GR mRNA expression was found in e.g., hippocampus, hypothalamus, cerebellum, raphe nuclei, locus coeruleus, and olfactory bulb, in midgestation from gestational day E12.5 onward $(16,42)$. At the end of the gestational period, when endogenous levels of corticosterone are high and the fetal HPA-axis becomes active, GR mRNA expression increases throughout the brain. MR mRNA expression is more limited in the hippocampus, parts of the hypothalamus and the superior colliculus piriform cortex, lateral septum, brainstem, and pituitary and starts in late gestation, 3 days before birth (16). A similar expression pattern was seen in mice (43-45).

In precocial species such as the guinea pig and sheep, a different and more complex MR and GR expression pattern was found (46-48). In guinea pigs, from gestational day 40 onward both MR and GR mRNA is present in the cortex, hippocampus, and dentate gyrus. In the period between gestational day 40 and 50, which is $60-75 \%$ of the total gestation length, GR mRNA levels increase while MR mRNA levels decrease. GR mRNA in the hippocampus increases to peak levels near term, while MR mRNA levels remain consistently low. However, in the paraventricular nucleus (PVN), GR mRNA levels are at peak level around gestational day 40 and 50 and show a large decline afterward (48).

\section{ANIMAL MODELS OF ANTENATAL GLUCOCORTICOID EXPOSURE}

Many experimental animal studies have demonstrated that glucocorticoid overexposure in utero, both endogenous and exogenous, can have long-term effects on the offspring. Studies in rodents have shown a relationship between antenatal glucocorticoid overexposure and signs of schizophrenia and depression, increased anxiety and impaired learning and memory [see review in Ref. (49)]. Antenatal glucocorticoid exposure in rats, guinea pigs, and non-human primates caused permanently elevated baseline corticosteroid levels and increased corticosteroid levels in response to stress (50-53). Excess antenatal glucocorticoids are also capable of permanently altering MR and GR expression in multiple brain areas (54-56) and can influence entire neurotransmitter systems $(49,57)$. Experimental animal studies in comparison to studies in man are far better capable of controlling variables, yet there are many differences in methodology that can influence the outcome, such as the type of stressor or synthetic glucocorticoid used and timing and duration of exposure. Additionally, the effects of glucocorticoid overexposure are also age, sex, and species specific, making it very difficult to translate the outcome of animal experiments to the clinic.

\section{POST-NATAL MR AND GR EXPRESSION}

The ontogeny of the receptors has been carefully mapped over the years using different techniques such as receptor binding assays, immunocytochemistry, and in situ hybridization (58-62). In general, MR is abundantly expressed in limbic-cortical regions, such as hippocampus, septum, amygdala, and fronto-cortical regions that have a function in processing of stressful information. With all detection methods, MR density is found to be high already early postnatally in mice and rats and localized in the nucleus. Pituitary GR expression is also very high in early-life. In the brain, GR binding and mRNA expression gradually increase postnatally and at weaning have reached about $50 \%$ of its adult level in the rat, and already adult levels in the mouse.

Using immunocytochemistry, a profound change in translocation of GR was observed. Immediately after birth, high nuclear immunoreactivity (ir) of GR occurs widespread over the rodent brain, particularly in stress regulating centers such as PVN, the ascending biogenic amine neurons, hippocampus, and amygdala as well as fronto-cortical regions. Then, possibly because of the low circulating levels of corticosterone during the SHRP, nuclear GR-ir is very low before reappearing at around pnd 12. Interestingly, the initial high GR-ir in the hippocampal CA3 pyramidal neurons and the suprachiasmatic nucleus does not re-appear after pnd 7, suggesting that the function of the latter nucleus now is entrained by exposure to daylight rather than the circadian variation in glucocorticoids from the mother $(63,64)$.

MR and GR in hippocampus show a profound downregulation after prolonged maternal absence, while a procedure like handling can induce their expression (65-67). Interestingly, MR and GR density changes in parallel with the amount of maternal care the pup is exposed to, a change in receptor concentration that can be explained by the extent of methylation of the receptor gene promotor region $(68,69)$. In a classical experiment $(70)$, infant rats were deprived of maternal contact for $24 \mathrm{~h}$ on pnd 3-4 and injected with saline or ACTH1-24 at the end of the deprivation period. They were then returned to their dams and weaned on pnd 21. At pnd 48 , they were sacrificed ( $24 \mathrm{~h}$ post adrenalectomy) and the hippocampal MR and GR measured using an in vitro cytosol binding assay. Using this procedure in the male rats, deprivation and deprivation + ACTH resulted in a reduction of GR. MR was also significantly downregulated in the deprived males. In contrast, in the female rats, saline injections in deprived female rats resulted in increased GR capacity and ACTH injections lead to a further up-regulation of the GR. None of the early manipulations influenced the regulation of the MR in females. These results in adult (7-week-old) rats indicate that the corticosteroid receptor systems in the brain are sensitive to brief manipulations in maternal care as well as corticosterone levels occurring early in development. Moreover, there is a striking effect of sex.

\section{ANIMAL MODELS OF ENDOGENOUS POST-NATAL GLUCOCORTICOID VARIATION}

In rodents, the first 2 weeks of life are characterized by a SHRP during which mild psychological stressors or exogenous ACTH, 
that trigger a pronounced corticosterone rise in adulthood, produce only a weak adrenocortical response $(71,72)$. The SHRP lasts from pnd 4 to 14 in rats, and from pnd 2 to 12 in mice (73). During the SHRP, circulating corticosterone levels are low and stable, but the steroid that circulates is free, since corticosteroid binding globulin (CBG) is not detectable during this period. Also metabolism of corticosterone is changed, and hence the pharmacodynamics of the hormone is different from that during the previous perinatal days as well as the postweaning period. Because of the lack of ACTH, the size of the adrenal is small and thus the capacity to secrete steroids is very low, demonstrating that adrenal hyporesponsiveness is actual the most proximal cause of the SHRP (74).

The mechanism underlying this period of adrenal quiescence has been examined thoroughly. It has been proposed that neural connections involved in processing of stressful information are still immature at the time. However, since adrenalectomy (ADX) during the SHRP triggers a large ACTH response, it seems that enhanced corticosterone feedback at the pituitary level is causal for the SHRP. Moreover, Schmidt et al. (75) demonstrated that the GR antagonist RU486, administered during the SHRP, triggered a profound $\mathrm{ACTH}$ and corticosterone response. Next, mice carrying a conditional knockout of the GR gene specifically targeted at the pituitary corticotrophs showed excessive amounts of circulating corticosterone during the SHRP (76). This elevated corticosterone was resistant to dexamethasone suppression suggesting that in the pup the pituitary is the primary feedback site of stress-induced HPA-axis activity. Indeed, a single exposure to a psychological stressor is capable to mount a central response in c-fos and CRH, but the adrenal remains quiescent under these conditions (77).

It is important to realize that GR-mediated feedback is in operation to maintain the SHRP and this phenomenon by definition only can be revealed in the context of a stressor. Hence, administration of RU486 in saline did not trigger a stress response and therefore no further disinhibition by the GR antagonist. If RU486 was administered in polyethylene glycol (PEG) as solvent, an immune response caused by inflammation at the injection site occurred that was sufficient to trigger adrenocortical corticosterone secretion revealing the effect of the antagonist (78).

Thus, during the SHRP, corticosterone inhibits the stressinduced HPA-axis activity primarily via a pituitary feedback site. The GR-mediated mechanism maintaining the SHRP can be revealed by pituitary GR knockout or GR antagonist treatment, but only if there is a corticosterone rise after stress. In case of resting conditions when GR blockade cannot operate because corticosterone levels are too low, the quiescence of the HPA-axis is maintained via a centrally driven MR mechanism. These MR's operate brain circuits appraising salient information as they do during adulthood (78).

\section{MATERNAL CARE AND NOT DEXAMETHASONE EXERTS LONG-TERM HPA-AXIS CONTROL}

There is evidence that the effects of dexamethasone on the developing brain precede independent of psychosocial and attachment effects. The experiments were inspired by the seminal studies of Levine in the 1950's demonstrating that daily handling of rat pups attenuated HPA-axis activity and emotional reactivity in adulthood, an effect that could be mimicked by enhanced maternal care $(71,72)$. MR and GR also respond; both handling and maternal care induced MR and GR, probably because of enhanced demethylation of the receptor gene $(68,79,80)$. The opposite outcome was reached under conditions of prolonged maternal absence, a procedure that has become known as maternal deprivation.

In response to $24 \mathrm{~h}$ of maternal deprivation of rat or mouse pups ACTH and corticosterone initially both rise during the first $8 \mathrm{~h}$ of maternal absence. Subsequently, the rise of corticosterone continues and reaches maximal levels after $24 \mathrm{~h}$, while ACTH levels normalize for the remainder of the $24 \mathrm{~h}$ period. With the rise of corticosterone, the pituitary pro-opiomelanocortin (POMC) and CRH- and GR mRNA levels decrease in the PVN (66). If these 24$\mathrm{h}$ deprived pups are exposed to an injection stressor a profound response occurs in pituitary ACTH and c-fos mRNA in the PVN. Amazingly, the pituitary ACTH and PVN c-fos response is normalized after stroking the pups for $45 \mathrm{~s}$ every $8 \mathrm{~h}$ with a warm wet artist brush in the anogenital region, mimicking maternal licking and grooming (81). For normalization of the corticosterone and the PVN GR mRNA response feeding is required in addition to stroking. Interestingly, dexamethasone $(100 \mu \mathrm{g} / \mathrm{kg})$ administration completely inhibits the ACTH and corticosterone response, but does not affect the central responses to maternal deprivation and the stressor (81) (Figure 1).

This differentiation between the effects of behavioral manipulations and the action of dexamethasone also persists. In a subsequent experiment, the rats deprived from pnd 11 to 12 for $24 \mathrm{~h}$ were pre-treated with dexamethasone to suppress the corticosterone response to maternal deprivation. Another group was only stroked for $45 \mathrm{~s}$ every $8 \mathrm{~h}$ or stroked + fed at that time, the latter procedure like dexamethasone also suppresses the deprivation-induced HPA-axis activity. At 20 days of age, the previously deprived + dexamethasone-treated animals did not differ in their endocrine and central responses. However, feeding and stroking did normalize the persistent effect of maternal deprivation on ACTH and corticosteroid receptors. Hence this study not only shows a lack of a persistent effect of dexamethasone, but also that the suppression of corticosterone by dexamethasone has no long-term consequences. It is the re-instatement of specific aspects of maternal care that counts in the long-term control of neuroendocrine function (82).

\section{PUPS BECOME USED TO REPEATED MATERNAL SEPARATION}

That the central components of the stress response are already in operation during the SHRP can be demonstrated also in another way. If the 24-h maternal deprivation at pnd 3-4 was split into three episodes of each $8 \mathrm{~h}$ per day from pnd 3 to 5 , we observed during the first separation the predicted rise in $\mathrm{ACTH}$ and corticosterone secretion. These neuroendocrine responses disappeared with the next separations as if the pup has learned to anticipate the return of the dam. When the anti-glucocorticoid RU486 was administered the response to the first separation was further enhanced, but the effect of the antagonist declined in the second and was abolished after the third separation on pnd 5. In contrast, a MR antagonist decreased corticosterone levels after the first, but increased corticosterone secretion after the third separation. Surprisingly, while 

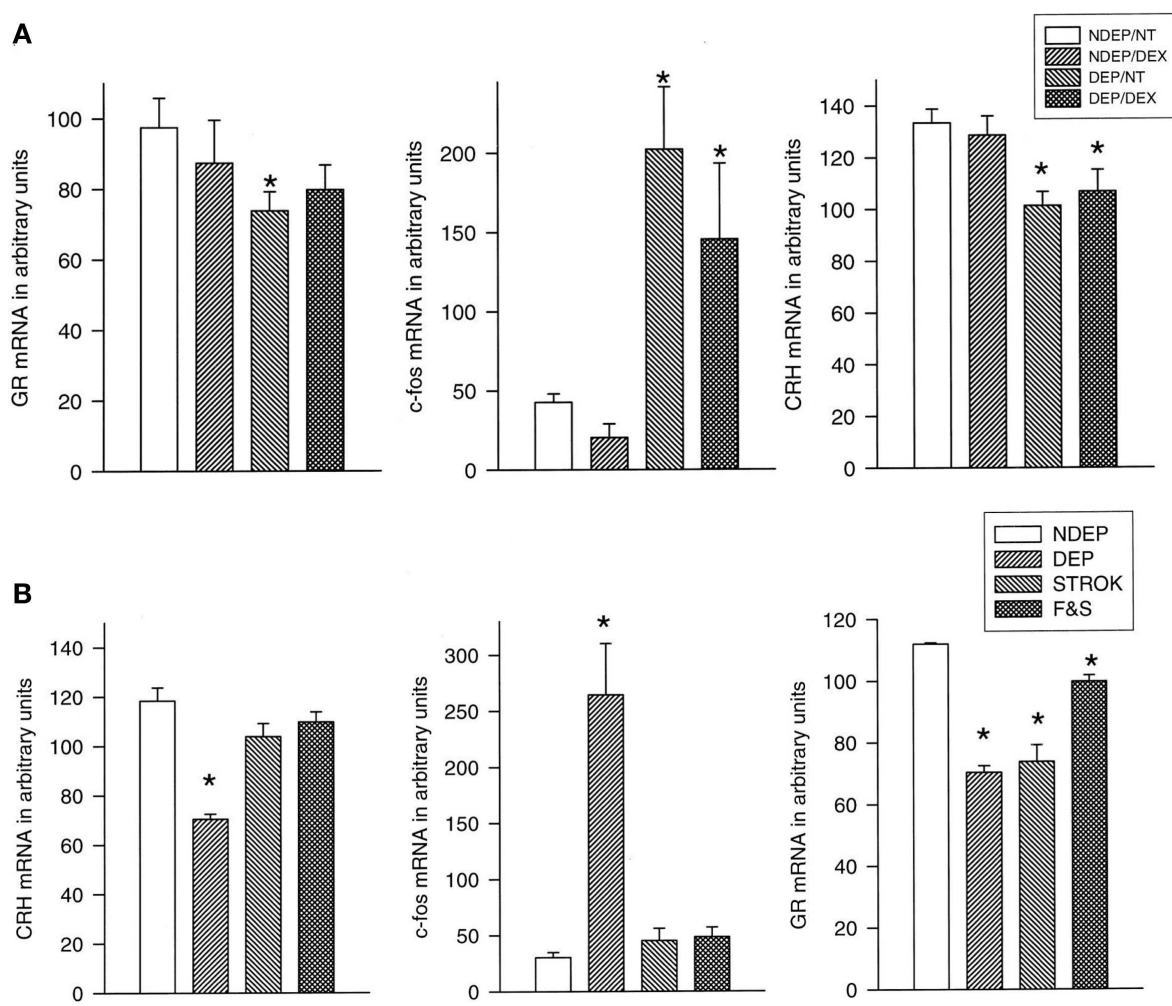

FIGURE 1 | Basal CRH stress-induced (30 min after saline injection) c-fos and basal GR mRNA expression in the PVN of 12-day-old pups. (A) Effect of dexamethasone (DEX): the deprived (DEP) group had been deprived $24 \mathrm{~h}$ before testing ( $n=10-12$ per group). Non-deprived (NDEP) animals served as controls. The DEX animals had received a dexamethasone injection at the onset of deprivation (or equivalent time for NDEP) of $100 \mu \mathrm{g} / \mathrm{kg} \mathrm{BW.} \mathrm{NT}$ animals had received a saline injection instead of a DEX injection, ${ }^{*} p<0.05$, significant from NDEP counterparts. (B) Effect of feeding and stroking: litters were deprived for $24 \mathrm{~h}$ on P11, during which time they were either left undisturbed (ISO), stroked (STROK), or stroked and episodically fed (F \& S) ( $n=10-12$ per group). NDEP animals served as controls, ${ }^{*} p<0.05$, significant from NDEP counterparts. [Reprinted with permission from Ref. (81)]. the newborn becomes used to repeated daily maternal separation as reflected by its normalization of basal HPA-axis activity to SHRP levels, the pups continue to respond to a novelty stressor $(78,83)$.

The importance of this information cannot be emphasized enough. It first shows that the pups as young as they are already have learned to cope with maternal absence. Their stress system stays on alert, however, and this process seems to involve the functioning of the MR. In the adult, this receptor has been shown to be important in controlling the circuits underlying the appraisal of salient events, vigilance, and emotional reactivity, and apparently this salience system already seems to be in operation in the newborn. In the adult amygdala, corticosterone is capable to impose metaplasticity in the amygdala $(8,84,85)$. It appears that also in the pup the cooperative MR- and GR-mediated actions of corticosterone can enhance a lasting activity in the amygdala as can be read from the increased c-fos activity that persists into later life $(86,87)$. Whether glucocorticoids acting via GR are capable early postnatally to reallocate energy resources to circuits underlying executive function as they do in the adult, remains to be demonstrated $(7,88-90)$. That at this early age likely the salient rather than the fronto-cortical network operates also has become apparent from studies demonstrating the efficacy of the MR-dependent network in response to corticosterone during the SHRP (91).
In these experiments not only the duration of the separation leaves its marks, also the timing is relevant. If $24 \mathrm{~h}$ of maternal separation occurs at pnd 3-4, an enhanced stress-induced ACTH and hypothalamic c-fos response is observed at pnd 20. Deprivation for $24 \mathrm{~h}$ at pnd 11-12, however, results in the opposite, an attenuated ACTH and c-fos response to stress 8 days later at pnd 20 (92). The corticosterone response to stress in the pnd 20 pups deprived at either pnd 3 or 11 was not different from the nondeprived controls, however. Accordingly, the persistent alterations in central and ACTH responses as a function of pnd of deprivation are not reflected in corticosterone levels.

In conclusion, the findings reported in the previous paragraphs demonstrate that post-natal dexamethasone effects are overridden by centrally regulated processes that underlie coping of the pup with changing conditions. The newborn is aware of these changing conditions and the corticosterone receptor system seems already to cooperate with the sympathetic nervous system in organizing the salience neuronal network response expressing signs of appraisal, attention, vigilance, and emotional reactivity. Why this network does not seem to be affected by dexamethasone may be because the synthetic steroid does not bind to the $\mathrm{MR}$, which is one of the initial drivers of the salience network (Figure 2). 

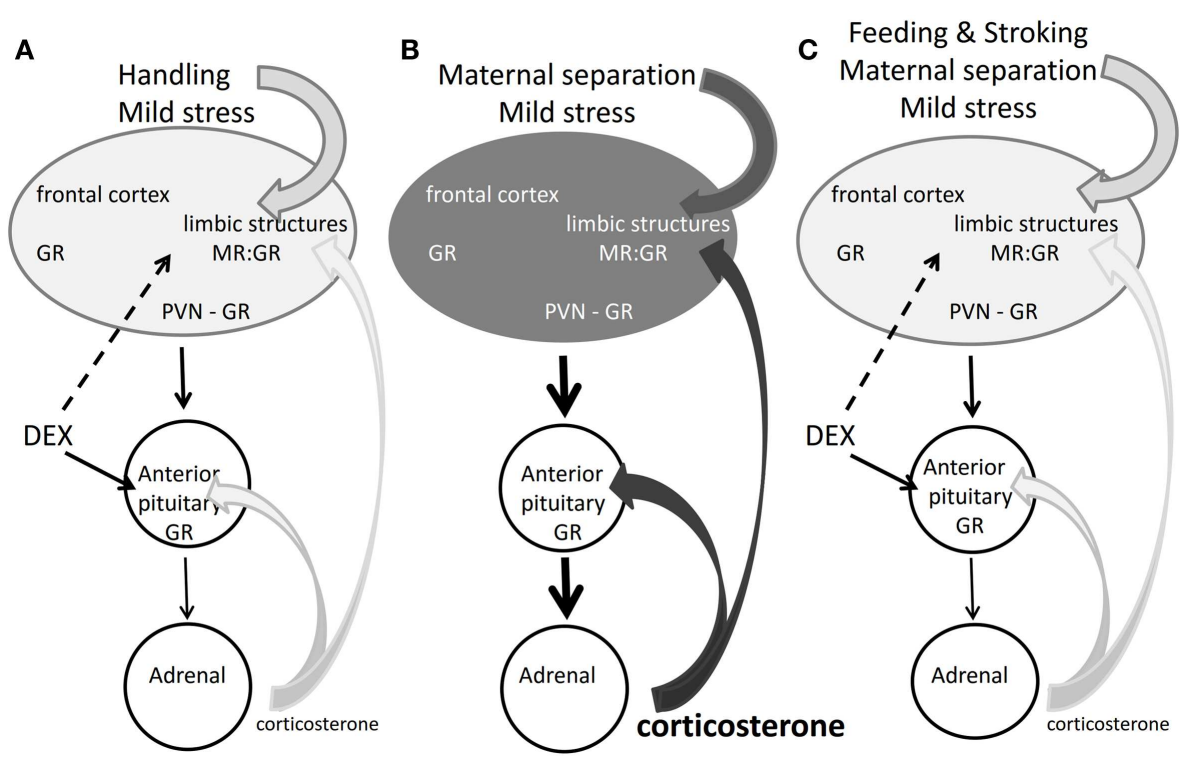

FIGURE 2 | Corticosterone, dexamethasone, and the rat SHRP. (A) Mild stress + handling: corticosterone maintains quiescence in the HPA-axis, but the brain responds to the mild stressor. Dexamethasone acts on brain and pituitary via GR. Handling obliterates long-term effects of dexamethasone (93). (B) Maternal separation and mild stress: stressful information from the brain overrides the pituitary feedback action of corticosterone. The elevated corticosterone acts via MR and GR to modulate programing of limbic brain pathways (87). The darker gray tone indicates enhanced limbic activity by increased sensory and corticosterone input. (C) Feeding and stroking the maternally separated rat inhibits the brain, pituitary, and adrenal response to the stressor. Dexamethasone also blocks the pituitary-adrenal axis but does not give the same outcome as feeding and stroking (81).

\section{ANIMAL MODELS OF POST-NATAL GLUCOCORTICOID EXPOSURE}

Animal models of post-natal treatment with dexamethasone have demonstrated profound effects on later life outcome. Among the most serious outcomes is the finding that the lifespan of early dexamethasone-treated rats was reduced with $25 \%$ (94). The cause of death was cardiac and kidney failure, while also auto-immunity was noted. Impaired cognitive functions were also reported. The dexamethasone-treated animals had deficits in spatial learning and showed disturbances in the neuroendocrine response pattern to stress $(95,96)$.

We started a research project with the aim to ameliorate the putative negative prognosis of early dexamethasone treatment. In the first series of experiments, we have used an intracerebroventricular (ICV) administration of the anti-glucocorticoid RU486 to protect the brain against early dexamethasone treatment (97). We adopted the treatment regimen of tapering daily doses of dexamethasone-21-phosphate during the first 3 pnds, because it is thought to resemble the clinical administration of the drug: $0.5 \mu \mathrm{g} / \mathrm{g}$ pup on pnd 1 followed by 0.3 and $0.1 \mu \mathrm{g}$ on pnd 2 and 3. The treatments were preceded by an ICV administration of $0.1 \mathrm{ng}$ RU486. First, we examined with immunostaining for the Ki67 marker the neuronal proliferation in the hippocampal dentate gyrus and found a profound reduction the day after dexamethasone treatment, which however was not inhibited by GR blockade. These effects were normalized by pnd 10. We also analyzed astrogliosis on the basis of glial fibrillary acidic protein (GFAP) immunocytochemistry and found a significant suppression in the corpus callosum 1 week after dexamethasone administration, that was blocked by pre-treatment with RU486 (Figure 3).
These data are consistent with previous studies showing that dexamethasone can transiently suppress neuronal proliferation and astrogliosis and that the effects are reversible possibly because of rebound effect later during development (98). The data also show that some of these effects can be prevented by local GR blockade in the hippocampus.

\section{LATER LIFE OUTCOME}

We were unable to reproduce the striking negative outcome of early post-natal dexamethasone treatment and discovered several factors that may account for this discrepancy with the published studies. First, in our studies we have used Long Evans rats, while most other studies were performed with Wistars or Sprague Dawley rats. More importantly, however, might have been differences in the design of the studies. While for instance Kamphuis et al. (96) used a whole litter design, we have consistently used a split-litter design with both dexamethasone and saline treated animals within every litter, to assure similar treatment conditions for each individual animal. Moreover, in the course of our experiments we noted that the handling procedure, required to inject and mark the pups, actually triggered bouts of enhanced maternal care that are known since long to reduce emotional reactivity and stress responsivity of the pups in later life. Indeed in a comparative study we found that a non-handled group of rats was more impaired in cognitive function than the handled dexamethasone and saline groups that each did not differ significantly from each other $(93,99)$.

Then in a controlled study, we examined whether daily handling actually could prevent adverse effects of post-natal dexamethasone treatment (93). Thus four groups were compared: first, a 


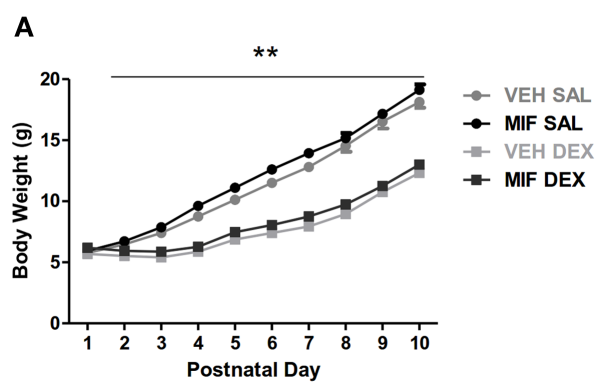

\section{PND10 Number of GFAP+ cells \\ Corpus Callosum}
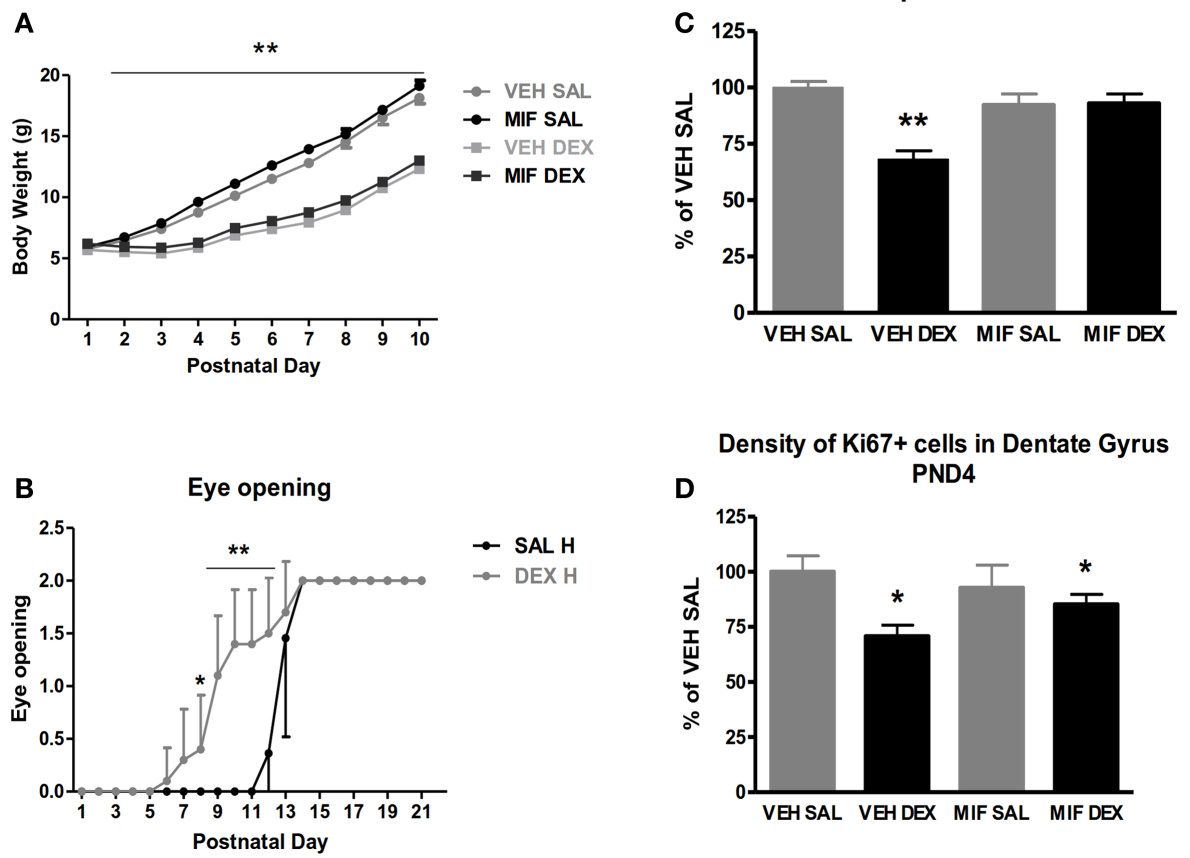

FIGURE 3 | Short-term effect of post-natal dexamethasone. (A) Body weight on pnd 1-10 of saline (SAL) and dexamethasone (DEX) treated animals with intracerebroventricular (ICV) treatment of the glucocorticoid antagonist RU486 (mifepristone, MIF). DEX treatment significantly reduced body weight; this effect is not prevented by central mifepristone pre-treatment. (B) DEX treatment resulted in accelerated eye opening; on pnd 8-12 DEX treated animals show enhanced level of eye opening

${ }^{* *} p<0.01$. (C) Number of glial fibrillary acidic protein (GFAP)-positive cells in the corpus callosum 7 days post treatment in SAL and DEX treated animals with ICV MIF pre-treatment. **Interaction between subcutaneous (SC) and ICV treatment $p<0.01$. "Interaction between SC and ICV treatment $p<0.10$. (D) Density of Ki-67 positive cells in the dentate gyrus of the hippocampus $24 \mathrm{~h}$ post treatment in SAL and DEX treated animals with ICV MIF pre-treatment. ${ }^{*}$ Main effect of DEX treatment $p<0.01$; ${ }^{*}$ main effect of DEX treatment $p<0.05$. [Reprinted with permission from Ref. (97)]. saline and a dexamethasone group that was only handled briefly for injections on the first 3 days of life and afterward was left undisturbed until weaning. Second, a saline and a dexamethasone group that was handled daily until weaning for $15 \mathrm{~min}$. Eye opening was accelerated in dexamethasone-treated animals from day 12 to 8; a phenomenon that could not be evaluated in the non-handled groups. Dexamethasone treatment reduced body weight gain by $20 \%$ during the first 3 weeks of life. These differences in body weight lasted up to 10 months of age. Maternal care was enhanced the first week of life in the handled groups. This effect was only observed post-reunion when licking and grooming was increased from about 8 to $12 \%$ of the time. These differences in maternal care are known to have profound effects on later life outcome (100).

A number of behavioral observations were made over the next 10 months. Handling improved impaired spatial learning of the dexamethasone-treated non-handled animals the T-maze (Figure 4). In another hippocampal-associated spatial learning test, the water maze, handling reduced the susceptibility to the impact of dexamethasone treatment. Furthermore, in a fear conditioning paradigm the acquisition of fear as expressed by a freezing response was reduced in both handling groups both immediately after the shock as well as upon re-exposure to the context after $24 \mathrm{~h}$, without any effect of dexamethasone treatment, which is in agreement with Kamphuis et al. (95). Handling had a beneficial effect on pre-pulse inhibition at the $2 \mathrm{~dB}$ level in saline treated animals, without affecting dexamethasone-treated animals. Finally, both dexamethasone treatment and handling resulted in enhanced negative feedback of the stress-induced corticosterone response and reduced startle reactivity (Figure 4). Thus, we find that the handling procedure, which enhances maternal care received by the newborn, was able to attenuate specific dexamethasoneinduced impairments in the behavioral phenotype of the adult animals (93).

\section{DEVELOPMENTAL ORIGIN OF DISEASE}

One may wonder how the outcome of early dexamethasone exposure may fit into the theory on the developmental origin of health and disease (DOHaD). This theory has its basis in the Barker hypothesis on the relationship between low birth weight and health outcome in later life and refers to the efficiency of food and energy transfer of the mother to the fetus (101). There can be many reasons for this deficit including the stressful events occurring antenatally and even the pre-implantation hormonal conditions (102). Ovarian hyperstimulation is a stressful condition that compromises vascularization of the blastocyst implantation site and hence caused decreased supply of nutrients. Ovarian hyperstimulation is commonly used in the generation of transgenic mice and might therefore have introduced a bias in all studies involving mutant 

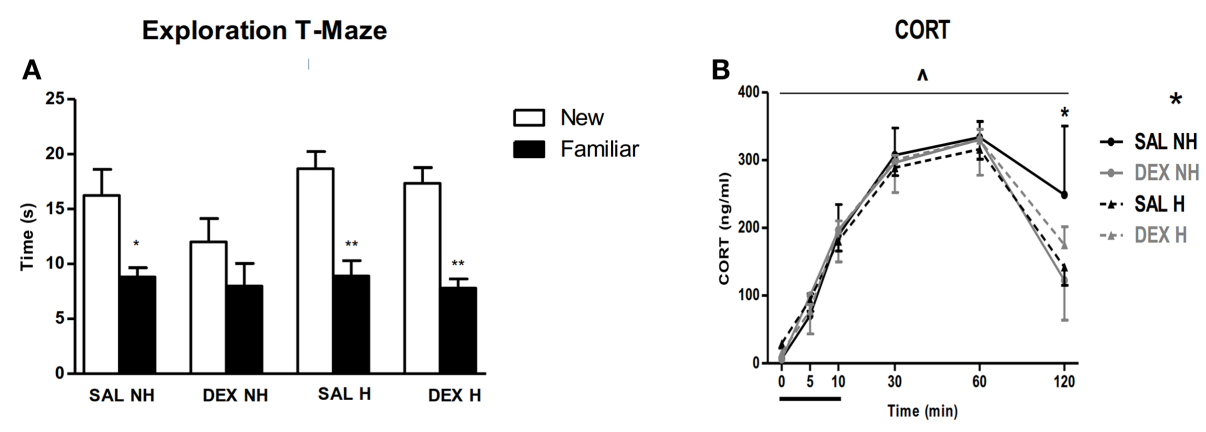

FIGURE 4 | Long-term outcome of post-natal dexamethasone. (A) All groups except dexamethasone non-handled (DEX NH) spent significantly more time in the new compared to the familiar arm during re-exposure to T-maze. Data represent mean \pm SEM, ${ }^{*} p<0.05,{ }^{*} p<0.01$. (B) Cortcosterone (CORT) levels before, during, and following exposure to 10 min restraint stress. Both handling and DEX treatment result in enhanced negative feedback of the HPA-axis at $t=120 \mathrm{~min}$. Data represent mean \pm SEM. Time $\times$ drug treatment $\times$ handling interaction $p=0.01,{ }^{*} p<0.05$ (from Ref. (93)). mice $(103,104)$, particularly if urinary rather than recombinant gonadotropins have been used.

The DOHaD theory describes how experiences during earlylife from blastocyst implantation, to fetal and post-natal life into puberty may induce developmental changes that affect the susceptibility to often comorbid cardiovascular and metabolic diseases as well as mental disorders in later life. It is thought that stressful experiences during early-life can modulate the genetic programing of specific brain circuits underlying emotional and cognitive aspects of behavioral adaptation. Although such a scenario implies multiple hits we have used for practical reasons to restrict the hits to three main categories: hit 1: genetic pre-disposition, hit 2: early-life experiences and hit 3: experiences during puberty $(87,105,106)$.

\section{CUMULATIVE STRESS EXPOSURE: THE MATCH/MISMATCH THEORY}

It was found that either each subsequent hit accumulates damage and predisposes for disease or that gene $\mathrm{X}$ environment in earlylife (hit $1 \times$ hit $2 \times$ hit 3 ) prepares for coping with challenges in later life. The latter situation predicts that experiencing adversity in early-life actually promotes coping with similar adverse conditions in later life. These findings led to the formulation of the predictive adaptive capacity or match/mismatch hypothesis (107). The latter hypothesis predicts increased vulnerability in case of a mismatch between early-life experiences that have re-programed the behavioral repertoire to cope with the actual circumstances the individual is facing in later life (108).

In our research, we observed that male rats that had experienced as pups abundant maternal care were well prepared at adulthood to execute cognitive tasks under relatively mild stressful conditions. Their hippocampus showed signs of extensive dendritic arborizations richly endowed by synaptic boutons and in vitro an efficient long-term potential (LTP) response could be evoked from these hippocampal circuits. However, under more stressful conditions this well-groomed offspring performed poorly, a finding that gives support to the match/mismatch hypothesis (100, 109-113).

What determines whether early-life adversity actually prepares for life ahead or for cumulative damage and enhanced vulnerability is not known. One line of research suggests that the genotype is critical. When newborn rats of a line that was genetically selected for enhanced responsiveness of the dopamine system by apomorphine-induced gnawing were deprived repeatedly from maternal care for a prolonged period, but only if the pups had also experienced a stressor (87). Subsequent exposure to isolation rearing during puberty promoted at adulthood signs of schizophrenia such as an impaired PPI response.

How early-life dexamethasone treatment fits into these hypothesis is not known. It is conceivable that the reduced body weight after pre- and post-natal dexamethasone exposure bears some relationship with the phenotype that led to the Barker and the DOHaD theories, but this needs to be investigated. At the same time, however, we also presented evidence that with respect to the brain the dexamethasone effects are overridden by maternal factors. This was demonstrated in two ways. First, in the deprived rat the normalization of HPA-axis activity persisted by mimicking maternal care through feeding and stroking the pups, but not if dexamethasone was given that also causes like maternal care an immediate suppression of the HPA axis. Second, adverse effects of dexamethasone on higher brain functions were ameliorated by neonatal handling causing enhanced maternal care.

\section{MECHANISM}

How do these maternal factors override the lasting effects of dexamethasone? Research in the past decade has clearly established that early-life experience may cause stable changes in histone acetylation and DNA methylation. These findings have led to the recognition of the epigenome as the molecular basis for altered plasticity in organ systems including the brain (114). These epigenomic signatures are a determinant of plasticity in neuronal networks underlying later emotional expression and cognitive performance, and seem a significant factor in the precipitation of stress-related mental disorders such as depression and addiction (115).

In recent years, DNA methylation of HPA-axis genes, among others the promotor regions of the GR $(80,116)$, the vasopressin (VP) gene (117), and 11ßHSD (118) was observed. In particular, the epigenetic change in GR was found associated with a 
behavioral response pattern and HPA-axis setpoint in later life, and therefore is considered to represent some sort of "molecular memory" for salient events (68). Hence, decreased expression of GR in the hippocampus was found associated with emotional neglect in early-life $(80,119)$. Suderman et al. (116) recently stated that a global epigenetic signature of early-life experience becomes apparent that is maintained across species and centered around GR gene regulation, while more detailed analysis of the methylation profile may reveal more subtle intrinsic differences between species. Indeed, altered responsiveness in gene expression is maintained until adulthood and reflected in transcriptome analysis of subregions of the hippocampus (120). In this type of analysis it appeared already in the adult animals that the history of chronic stress experience causes a profound change in the transcriptional response to an acute corticosterone or stress stimulus with an overrepresentation of genes involved in chromatin remodeling, epigenetic processes, and cell adhesion (121-123).

The mechanism by which perinatal dexamethasone exposure causes long-term effects is not completely understood. Recent studies suggest that these long-term effects are possibly mediated through GR-activated epigenetic modulations such as DNA methylation and histone acetylation. Matthews and colleagues have extensively studied the epigenetic modifications associated with antenatal synthetic glucocorticoid treatment in the guinea pig. They observed that during the endogenous glucocorticoid surge in late gestation considerable changes in global DNA methylation in several organ systems take place that affect the expression of genes involved in the methylation process. Betamethasone administered before the natural glucocorticoid surge also affected global methylation and expression of methylation-related genes, though slightly different compared to the endogenous surge, and in addition affected histone-3 lysine 9 acetylation $(124,125)$. The effects of betamethasone treatment not only persisted into adulthood but also into the next generation (124).

In the male hippocampus it was also shown that concurrent with changes in DNA methylation, GR DNA binding was altered during both the endogenous glucocorticoid surge as well as synthetic glucocorticoid treatment (126). Though, this study clearly shows a relationship between altered GR DNA binding and epigenetic changes in gene expression, further research is necessary to provide conclusive evidence for a GR-mediated mechanism of epigenetic modification. This type of ChIP-seq analysis of GR binding to the hippocampal genome of ADX rats recently identified in the adult rat hippocampus 2460 significant binding sites of which $40 \%$ were associated with GRE's in promoter regions (127).

\section{CONCLUDING REMARKS}

This contribution was focused on the mode and mechanism of action in the brain of perinatal dexamethasone administration using pre- and post-natal animal models. This topic is of relevance because glucocorticoids are critical for survival of prematurely born infants. The glucocorticoid is required to ensure adequate maturation of in particular lung tissue. Regarding the mode of action the timing of glucocorticoids is important. If given preterm to the mother the synthetic glucocorticoids are used in a restricted number of courses [see Cochrane data base, (128)]. Hydrocortisone is ineffective preterm since the hormone is largely inactivated by $11 \beta$-HSD 2 and does only poorly pass the placenta barrier. Postnatally hydrocortisone is used and reportedly there is so far no noticeable adverse outcome in later life (129). The underlying mechanism of the steroid effects depends on epigenetic modulation of the stress response system and possibly the changes in plasticity of limbic-forebrain glucocorticoid target regions.

The rodent is frequently used to examine adversity of dexamethasone treatment, because it is an altricial species and pnd 1 in the rat resembles the developmental stage at the beginning of the third trimester of human pregnancy. Alternatively, guinea pigs are used to mimic antenatal administration of dexamethasone to pregnant females. Here, we have discussed in extenso the role of glucocorticoids in development of the brain in relation to the HPA-axis. Some authors reported alarming effects of perinatal dexamethasone on health and brain development even causing a life shortening of 25\% (94). However, we and others (130) were unable to find these detrimental effects, probably because our design included enhanced levels of maternal care. Using two different approaches, we demonstrated that such maternal care effects override dexamethasone effects in the brain and the HPAaxis. Hence, other approaches based on environmental input may be beneficial. For instance, in rats environmental enrichment during puberty appeared to neutralize the adverse outcome in the offspring of antenatally stressed pregnant dams (131).

Hence context is capable to modulate the outcome of perinatal glucocorticoid action. The context becomes manifest in two ways. First, maternal care and probably other contextual factors such as e.g., environmental enrichment are capable to modulate the outcome of glucocorticoid action, possibly by an epigenetic machinery. Second, context is equally important in later life where it either does or does not match the phenotype shaped by early experiences in sensitive windows of brain development during early post-natal life and puberty. Probably depending on genotype and epigenomic signature susceptibility to stress-related disorders may develop. Because of this interaction between dexamethasoneinduced effects and experience-related factors, behavioral interventions appear to be crucial in the clinical management of preterm babies (132-134).

\section{ACKNOWLEDGMENTS}

The support by the Royal Netherlands Academy of Arts and Sciences and Eu-Lifespan is gratefully acknowledged.

\section{REFERENCES}

1. Padbury JF, Ervin MG, Polk DH. Extrapulmonary effects of antenatally administered steroids. J Pediatr (1996) 128(2):167-72. doi:10.1016/S0022-3476(96) 70384-0

2. Roberts D, Dalziel S. Antenatal corticosteroids for accelerating fetal lung maturation for women at risk of preterm birth. Cochrane Database Syst Rev (2006) 3:CD004454. doi:10.1002/14651858.CD004454.pub2

3. Barrington KJ. The adverse neuro-developmental effects of postnatal steroids in the preterm infant: a systematic review of RCTs. BMC Pediatr (2001) 1:1. doi:10.1186/1471-2431-1-1

4. Barrington KJ. Postnatal steroids and neurodevelopmental outcomes: a problem in the making. Pediatrics (2001) 107(6):1425-6. doi:10.1542/peds. 107.6.1425

5. Yeh TF, Lin YJ, Lin HC, Huang CC, Hsieh WS, Lin CH, et al. Outcomes at school age after postnatal dexamethasone therapy for lung disease of prematurity. N Engl J Med (2004) 350:1304-13. doi:10.1056/NEJMoa032089 
6. Reul JM, de Kloet ER. Two receptor systems for corticosterone in rat brain: microdistribution and differential occupation. Endocrinology (1985) 117(6):2505-11. doi:10.1210/endo-117-6-2505

7. de Kloet ER, Joëls M, Holsboer F. Stress and the brain: from adaptation to disease. Nat Rev Neurosci (2005) 6(6):463-75. doi:10.1038/nrn1683

8. Karst H, Berger S, Turiault M, Tronche F, Schütz G, Joëls M. Mineralocorticoid receptors are indispensable for non-genomic modulation of hippocampal glutamate transmission by corticosterone. Proc Natl Acad Sci U S A (2005) 102(52):19204-7. doi:10.1073/pnas.0507572102

9. Grossmann C, Scholz T, Rochel M, Bumke-Vogt C, Oelkers W, Pfeiffer AF, et al. Transactivation via the human glucocorticoid and mineralocorticoid receptor by therapeutically used steroids in CV-1 cells: a comparison of their glucocorticoid and mineralocorticoid properties. Eur J Endocrinol (2004) 151(3):397-406. doi:10.1530/eje.0.1510397

10. Rosenthal HE, Slaunwhite WR Jr, Sandberg AA. Transcortin: a corticosteroidbinding protein of plasma. X. Cortisol and progesterone interplay and unbound levels of these steroids in pregnancy. J Clin Endocrinol Metab (1969) 29(3):352-67. doi:10.1210/jcem-29-3-352

11. Mastorakos G, Illias I. Maternal and fetal hypothalamic-pituitary-adrenal axes during pregnancy and postpartum. Ann N Y Acad Sci (2003) 997:136-49. doi:10.1196/annals.1290.016

12. Riley SC, Challis JR. Corticotrophin-releasing hormone production by the placenta and fetal membranes. Placenta (1991) 12(2):105-19. doi:10.1016/01434004(91)90015-8

13. Davis EP, Sandman CA. The timing of prenatal exposure to maternal cortisol and psychosocial stress is associated with human infant cognitive development. Child Dev (2010) 81(1):131-48. doi:10.1111/j.1467-8624.2009. 01385.x

14. Edwards CR, Benediktsson R, Lindsay RS, Seckl JR. Hydroxysteroid dehydrogenase: key enzymes in determining tissue-specific glucocorticoid effects. Steroids (1996) 61(4):263-9. doi:10.1016/0039-128X(96)00033-5

15. Welberg LA, Seckl JR, Holmes MC. Inhibition of 11beta-hydroxysteroid dehydrogenase, the foeto-placental barrier to maternal glucocorticoids, permanently programs amygdala GR mRNA expression and anxiety-like behaviour in the offspring. Eur J Neurosci (2000) 12(3):1047-54. doi:10.1046/j.1460-9568. 2000.00958.x

16. Diaz R, Brown RW, Seckl JR. Distinct ontogeny of glucocorticoid and mineralocorticoid receptor and $11 \beta$-hydroxysteroid dehydrogenase types I and II mRNAs in the fetal rat brain suggest a complex control of glucocorticoid actions. J Neurosci (1998) 18(7):2570-80.

17. Ohkawa T, Takeshita S, Murase T, Kambegawa A, Okinaga S, Arai K. Ontogeny of the response of the hypothalamic-pituitary-adrenal axis to maternal immobilization stress in rats. Endocrinol Jpn (1991) 38(2):187-94. doi:10.1507/ endocrj1954.38.187

18. Reichardt HM, Schütz G. Feedback control of glucocorticoid production is established during fetal development. Mol Med (1996) 2(6):735-44.

19. Condon J, Gosden C, Gardener D, Nickson P, Hewison M, Howie AJ, et al. Expression of type 2 11beta-hydroxysteroid dehydrogenase and corticosteroid hormone receptors in early human fetal life. J Clin Endocrinol Metab (1998) 83(12):4490-7. doi:10.1210/jcem.83.12.5302

20. Noorlander CW, de Graan PN, Middeldorp J, van Beers JJ, Visser GH. Ontogeny of hippocampal corticosteroid receptors: effects of antenatal glucocorticoids in human and mouse. J Comp Neurol (2006) 499(6):924-32. doi:10.1002/cne.21162

21. Bayer SA, Altmann J, Russo RJ, Zhang X. Timetables of neurogenesis in the human brain based on experimentally determined patterns in the rat. Neurotoxicology (1993) 14(1):83-144.

22. Dobbing J, Sands J. Comparative aspects of the brain growth spurt. Early Hum Dev (1979) 3(1):79-83. doi:10.1016/0378-3782(79)90022-7

23. Liggins GC, Howie RN. A controlled trial of antepartum glucocorticoid treatment for prevention of the respiratory distress syndrome in premature infants. Pediatrics (1972) 50(4):515-25.

24. Crowther CA, Harding JE. Repeat doses of prenatal corticosteroids for women at risk of preterm birth for preventing neonatal respiratory disease. Cochrane Database Syst Rev (2007) 3:CD003935. doi:10.1002/14651858.CD003935.pub2

25. Susser ES, Lin SP. Schizophrenia after prenatal exposure to Dutch hunger winter of 1944-1945. Arch Gen Psychiatry (1996) 49(12):983-8. doi:10.1001/archpsyc. 1992.01820120071010
26. Brown AS, Susser ES, Lin SP, Neugebauer R, Gorman JM. Increased risk of affective disorder in males after second trimester prenatal exposure to the Dutch hunger winter of 1944-1945. Br J Psychiatry (1995) 166:601-60. doi:10.1192/bjp.166.5.601

27. Franzek EJ, Sprangers N, Janssens AC, van Duijn CM, van de Wetering BJ. Prenatal exposure to the 1944-45 Dutch 'hunger winter' and addiction in later life. Addiction (2008) 103(3):433-8. doi:10.1111/j.1360-0443.2007. 02084.x

28. Roseboom TJ, Painter RC, van Abeelen AF, Veenendaal MV, de Rooij SR. Hungry in the womb: what are the consequences? Lessons from the Dutch famine. Maturitas (2011) 70:141-5. doi:10.1016/j.maturitas.2011.06.017

29. Watson JB, Mednick SA, Huttenen M, Wang X. Prenatal teratogens and the development of adult mental illness. Dev Psychopathol (1999) 11(3):457-66. doi:10.1017/S0954579499002151

30. Ward AJ. A comparison and analysis of the presence of family problems during pregnancy of mothers of "autistic" children and mothers of normal children. Child Psychiatry Hum Dev (1990) 20(4):279-88. doi:10.1007/BF00706020

31. Meyer U, Feldon J. Epidemiology-driven neurodevelopmental animal models of schizophrenia. Prog Neurobiol (2010) 90:285-326. doi:10.1016/j.pneurobio. 2009.10.018

32. Beydoun H, Saftlas AF. Physical and mental health outcomes of prenatal maternal stress in human and animal studies: a review of recent evidence. Paediatr Perinat Epidemiol (2008) 22:438-66. doi:10.1111/j.1365-3016.2008. 00951

33. Heim C, Nemeroff CB. The role of childhood trauma in the neurobiology of mood and anxiety disorders: preclinical and clinical studies. Biol Psychiatry (2001) 49:1023-39. doi:10.1016/S0006-3223(01)01157-X

34. Hornung OP, Heim CM. Gene-environment interactions and intermediate phenotypes: early trauma and depression. Front Endocrinol (Lausanne) (2014) 5:14. doi:10.3389/fendo.2014.00014

35. Marques AH, O'Connor TG, Roth C, Susser E, Bjørke-Monsen AL. The influence of maternal prenatal and early childhood nutrition and maternal prenatal stress on offspring immune system development and neurodevelopmental disorders. Front Neurosci (2013) 31(7):120. doi:10.3389/fnins.2013.00120

36. Blanford AT, Murphy BE. In vitro metabolism of prednisolone, dexamethasone, betamethasone, and cortisol by the human placenta. Am J Obstet Gynecol (1977) 127(3):264-7.

37. Murphy VE, Fittock RJ, Zarzycki PK, Delahunty MM, Smith R, Clifton VL. Metabolism of synthetic steroids by the human placenta. Placenta (2007) 28(1):39-46. doi:10.1016/j.placenta.2005.12.010

38. Iqbal M, Gibb W, Matthews SG. Corticosteroid regulation of P-glycoprotein in the developing blood-brain barrier. Endocrinology (2011) 152(3):1067-79. doi:10.1210/en.2010-1227

39. Meijer OC, de Lange EC, Breimer DD, de Boer AG, Workel JO, de Kloet ER. Penetration of dexamethasone into brain glucocorticoid targets is enhanced in mdr1A P-glycoprotein knockout mice. Endocrinology (1998) 139(4):1789-93. doi:10.1210/endo.139.4.5917

40. Karssen AM, Meijer OC, van der Sandt IC, Lucassen PJ, de Lange EC, de Boer AG, et al. Multidrug resistance P-glycoprotein hampers the access of cortisol but not of corticosterone to mouse and human brain. Endocrinology (2001) 142:2686-94. doi:10.1210/endo.142.6.8213

41. Karssen AM, Meijer OC, Berry A, Sanjuan Piñol R, de Kloet ER. Low doses of dexamethasone can produce a hypocorticosteroid state in the brain. Endocrinology (2005) 146(12):5587-95. doi:10.1210/en.2005-0501

42. Cintra A, Solfrini V, Bunneman B, Okret S, Bortolotti F, Gustafsson JA, et al. Prenatal development of glucocorticoid receptor gene expression and immunoreactivity in the rat brain and pituitary gland: a combined in situ hybridization and immunocytochemistry analysis. Neuroendocrinology (1993) 57(6):1133-47. doi:10.1159/000126480

43. Brown RW, Diaz R, Robson AC, Kotelevtsev YV, Mullins JJ, Kaufman MH, et al. The ontogeny of $11 \beta$-hydroxysteroid dehydrogenase type 2 and mineralocorticoid receptor gene expression reveal intricate control of glucocorticoid action in development. Endocrinology (1996) 137(2):794-7. doi:10.1210/endo.137.2. 8593833

44. Speirs HJ, Seckl JR, Brown JR. Ontogeny of glucocorticoid receptor and $11 \beta$-hydroxysteroid dehydrogenase type-1 gene expression identifies potential critical periods of glucocorticoid susceptibility during development. J Endocrinol (2004) 181(1):105-16. doi:10.1677/joe.0.1810105 
45. Thompson A, Han VK, Yang K. Differential expression of $11 \beta$-hydroxysteroid dehydrogenase types 1 and 2 mRNA and glucocorticoid receptor protein during mouse embryonic development. J Steroid Biochem Mol Biol (2004) 88(45):367-75. doi:10.1016/j.jsbmb.2003.12.014

46. Yang K, Haynes NB, Lamming GE. Changes in glucocorticoid receptor number in the hypothalamus and pituitary of the sheep fetus with gestational age and after adrenocorticotropin treatment. Endocrinology (1990) 126(1):11-7. doi:10.1210/endo-126-1-11

47. Andrews MH, Matthews SG. Regulation of glucocorticoid receptor mRNA and heat shock protein 70 mRNA in the developing sheep brain. Brain Res (2000) 878(1-2):174-82. doi:10.1016/S0006-8993(00)02735-9

48. Matthews SG. Dynamic changes in glucocorticoid and mineralocorticoid receptor mRNA in the developing guinea pig brain. Brain Res Dev Brain Res (1998) 107(1):123-32. doi:10.1016/S0165-3806(98)00008-X

49. Huizink AC, Mulder EJ, Buitelaar JK. Prenatal stress and risk for psychopathology: specific effects or induction of general susceptibility? Psychol Bull (2004) 130(1):115-42. doi:10.1037/0033-2909.130.1.115

50. Levitt NS, Lindsay RS, Holmes MC, Seckl JR. Dexamethasone in the last week of pregnancy attenuates hippocampal glucocorticoid receptor gene expression and elevates blood pressure in the adult offspring in the rat. Neuroendocrinology (1996) 64(6):412-8. doi:10.1159/000127146

51. Owen D, Matthews SG. Prenatal glucocorticoid exposure alters hypothalamicpituitary-adrenal function in juvenile guinea pigs. J Neuroendocrinol (2007) 19(3):172-80. doi:10.1111/j.1365-2826.2006.01517.x

52. Uno H, Eisele S, Sakai A, Shelton S, Baker E, DeJesus O, et al. Neurotoxicity of glucocorticoid in the primate brain. Horm Behav (1994) 28(4):336-48. doi:10.1006/hbeh.1994.1030

53. Muneoka K, Mikuni M, Ogawa T, Kitera K, Kamei K, Takigawa M, et al. Prenatal dexamethasone exposure alters brain monoamine metabolism and adrenocortical response in rat offspring. Am J Physiol (1997) 273(5):R1669-75.

54. Henry C, Kabbaj M, Simon H, Le Moal M, Maccari S. Prenatal stress increases the hypothalamo-pituitary-adrenal axis response in young and adult rats. J Neuroendocrinol (1994) 6(3):341-5. doi:10.1111/j.1365-2826.1994. tb00591.x

55. Barbazanges A, Piazza PV, Le Moal M, Maccari S. Maternal glucocorticoid secretion mediates long-term effects of prenatal stress. J Neurosci (1996) 16(12):3943-9.

56. Tronche F, Kellendonk C, Kretz O, Gass P, Anlag K, Orban PC, et al. Disruption of the glucocorticoid receptor gene in the nervous system results in reduced anxiety. Nat Genet (1999) 23(1):99-103. doi:10.1038/12703

57. Virdee K, McArthur S, Brischoux F, Caprioli D, Ungless MA, Robbins TW, et al. Antenatal glucocorticoid treatment induces adaptations in adult midbrain dopamine neurons, which underpin sexually dimorphic behavioral resilience. Neuropsychopharmacology (2013) 39:1-12. doi:10.1038/npp.2013.196

58. Rosenfeld P, Sutanto W, Levine S, de Kloet ER. Ontogeny of type I and type II corticosteroid receptors in the rat hippocampus. Brain Res (1988) 42(1):113-8. doi:10.1016/0165-3806(88)90206-4

59. Rosenfeld P, van Eekelen JA, Levine S, de Kloet ER. Ontogeny of the type 2 glucocorticoid receptor in discrete rat brain regions: an immunocytochemical study. Brain Res (1988) 42(1):119-27. doi:10.1016/0165-3806(88) 90207-6

60. Rosenfeld P, Sutanto W, Levine S, de Kloet ER. Ontogeny of mineralocorticoid (type 1) receptors in brain and pituitary: an in vivo autoradiographical study. Brain Res Dev Brain Res (1990) 52(1-2):57-62. doi:10.1016/0165-3806(90) 90221-J

61. Rosenfeld P, van Eekelen JA, Levine S, de Kloet ER. Ontogeny of corticosteroid receptors in the brain. Cell Mol Neurobiol (1993) 13(4):295-319. doi:10.1007/BF00711575

62. van Eekelen JA, Bohn MC, de Kloet ER. Postnatal ontogeny of mineralocorticoid and glucocorticoid receptor gene expression in regions of the rat tel- and diencephalon. Brain Res Dev Brain Res (1991) 61(1):33-43. doi:10.1016/0165-3806(91)90111-U

63. van Eekelen JAM, Rosenfeld P, Levine S, Westphal HM, de Kloet ER. Postnatal disappearance of glucocorticoid receptor immunoreactivity. Neurosci Res Commun (1987) 1:129-33.

64. de Kloet ER, Han F, Meijer OC. From the stalk to down-under: about glucocorticoid receptors, stress and development. Neurochem Res (2008) 33(4):637-42. doi:10.1007/s11064-007-9520-9
65. Vázquez DM, Van Oers HJ, Levine S, Akil H. Regulation of glucocorticoid and mineralocorticoid receptor mRNAs in the hippocampus of the maternally deprived infant rat. Brain Res (1996) 731(1-2):79-90. doi:10.1016/S00068993(96)00465-9

66. Schmidt MV, Oitzl MS, Levine S, de Kloet ER. The HPA system during the postnatal development of CD1 mice and the effects of maternal deprivation. Brain Res Dev Brain Res (2002) 139(1):39-49. doi:10.1016/S0165-3806(02) 00519-9

67. Liu D, Diorio J, Tannenbaum B, Caldji C, Francis D, Freedman A, et al. Maternal care, hippocampal glucocorticoid receptors, and hypothalamic-pituitaryadrenal responses to stress. Science (1997) 277(5332):1659-62. doi:10.1126/ science.277.5332.1659

68. Meaney MJ, Szyf M, Seckl JR. Epigenetic mechanisms of perinatal programming of hypothalamic-pituitary-adrenal function and health. Trends Mol Med (2007) 13(7):269-77. doi:10.1016/j.molmed.2007.05.003

69. Oberlander TF, Weinberg J, Papsdorf M, Grunau R, Misri S, Devlin AM. Prenatal exposure to maternal depression, neonatal methylation of human glucocorticoid receptor gene $(\mathrm{NR} 3 \mathrm{C} 1)$ and infant cortisol stress responses. Epigenetics (2008) 3(2):97-106. doi:10.4161/epi.3.2.6034

70. Sutanto W, Rosenfeld P, de Kloet ER, Levine S. Long-term effects of neonatal maternal deprivation and ACTH on hippocampal mineralocorticoid and glucocorticoid receptors. Brain Res Dev Brain Res (1996) 92(2):156-63. doi:10.1016/0165-3806(95)00213-8

71. Levine S. Infantile experience and resistance to physiological stress. Science (1957) 126(3270):405. doi:10.1126/science.126.3270.405

72. Levine S. Developmental determinants of sensitivity and resistance to stress. Psychoneuroendocrinology (2005) 30(1):939-46. doi:10.1016/j.psyneuen.2005. 03.013

73. Schmidt MV, Enthoven L, van der Mark M, Levine S, de Kloet ER, Oitzl MS. The postnatal development of the hypothalamic-pituitary-adrenal axis in the mouse. Int J Dev Neurosci (2003) 21(3):125-32. doi:10.1016/S0736-5748(03) 00030-3

74. Rosenfeld P, Suchecki D, Levine S. Multifactorial regulation of the hypothalamic-pituitary-adrenal axis during development. Neurosci Biobehav Rev (1992) 16(4):553-68. doi:10.1016/S0149-7634(05)80196-4

75. Schmidt MV, Levine S, Oitzl MS, van der Mark M, Müller MB, Holsboer F, et al. Glucocorticoid receptor blockade disinhibits pituitary-adrenal activity during the stress hyporesponsive period of the mouse. Endocrinology (2005) 146(3):1458-64. doi:10.1210/en.2004-1042

76. Schmidt MV, Sterlemann V, Wagner K, Niederleitner B, Ganea K, Liebl C, et al. Postnatal glucocorticoid excess due to pituitary glucocorticoid receptor deficiency: differential short- and long-term consequences. Endocrinology (2009) 150(6):2709-16. doi:10.1210/en.2008-1211

77. Smith MA, Kim SY, van Oers HJ, Levine S. Maternal deprivation and stress induce immediate early genes in the infant rat brain. Endocrinology (1997) 138(11):4622-8. doi:10.1210/endo.138.11.5529

78. Enthoven L, Oitzl MS, Koning N, van der Mark M, de Kloet ER. Hypothalamicpituitary-adrenal axis activity of newborn mice rapidly desensitizes to repeated maternal absence but becomes highly responsive to novelty. Endocrinology (2008) 149(12):6366-77. doi:10.1210/en.2008-0238

79. Francis D, Diorio J, Liu D, Meaney MJ. Nongenomic transmission across generations of maternal behavior and stress responses in the rat. Science (1999) 286(5442):1155-8. doi:10.1126/science.286.5442.1155

80. Weaver IC, Cervoni N, Champagne FA, D’Alessio AC, Sharma S, Seckl JR, et al. Epigenetic programming by maternal behavior. Nat Neurosci (2004) 7(8):847-54. doi:10.1038/nn1276

81. van Oers HJ, de Kloet ER, Whelan T, Levine S. Maternal deprivation effect on the infant's neural stress markers is reversed by tactile stimulation and feeding but not by suppressing corticosterone. J Neurosci (1998) 18(23):10171-9.

82. van Oers HJ, de Kloet ER, Levine S. Persistent effects of maternal deprivation on HPA regulation can be reversed by feeding and stroking, but not by dexamethasone. J Neuroendocrinol (1999) 11(8):581-8. doi:10.1046/j.1365-2826. 1999.00329.x

83. Daskalakis NP, Claessens SE, Laboyrie JJ, Enthoven L, Oitzl MS, Champagne $\mathrm{DL}$, et al. The newborn rat's stress system readily habituates to repeated and prolonged maternal separation, while continuing to respond to stressors in context dependent fashion. Horm Behav (2011) 60(2):165-76. doi:10.1016/j. yhbeh.2011.04.003 
84. Karst H, Berger S, Erdmann G, Schütz G, Joëls M. Metaplasticity of amygdalar responses to the stress hormone corticosterone. Proc Natl Acad Sci US A (2010) 107(32):14449-54. doi:10.1073/pnas.0914381107

85. Joëls M, Sarabdjitsingh RA, Karst H. Unraveling the time domains of corticosteroid hormone influences on brain activity: rapid, slow, and chronic modes. Pharmacol Rev (2012) 64(4):901-38. doi:10.1124/pr.112.005892

86. Moriceau S, Wilson DA, Levine S, Sullivan RM. Dual circuitry for odorshock conditioning during infancy: corticosterone switches between fear and attraction via amygdala. J Neurosci (2006) 26(25):6737-48. doi:10.1523/ JNEUROSCI.0499-06.2006

87. Daskalakis NP, Diamantopoulou A, Claessens SE, Remmers E, Tjälve M, Oitzl MS, et al. Early experience of a novel-environment in isolation primes a fearful phenotype characterized by persistent amygdala activation. Psychoneuroendocrinology (2014) 39:39-57. doi:10.1016/j.psyneuen.2013.09.021

88. Myers B, McKlveen JM, Herman JP. Neural regulation of the stress response: the many faces of feedback. Cell Mol Neurobiol (2012) 32(5):683-94. doi:10. 1007/s10571-012-9801-y

89. Hermans EJ, Henckens M, Joëls M, Fernandez G. Dynamic adaptation of largescale brain networks in response to acute stressors. Trends Neurosci (2014) 37:304-14. doi:10.1016/j.tins.2014.03.006

90. de Kloet ER. From receptor balance to rational glucocorticoid therapy. Endocrinology (2014). doi:10.1210/en.2014-1048

91. van Oers HJ, de Kloet ER, Li C, Levine S. The ontogeny of glucocorticoid negative feedback: influence of maternal deprivation. Endocrinology (1998) 139(6):2838-46. doi:10.1210/endo.139.6.6037

92. van Oers HJ, de Kloet ER, Levine S. Early vs. late maternal deprivation differentially alters the endocrine and hypothalamic responses to stress. Brain Res Dev Brain Res (1998) 111(2):245-52. doi:10.1016/S0165-3806(98)00143-6

93. Claessens SE, Daskalakis NP, Oitzl MS, de Kloet ER. Early handling modulates outcome of neonatal dexamethasone exposure. Horm Behav (2012) 62(4):433-41. doi:10.1016/j.yhbeh.2012.07.011

94. Kamphuis PJ, de Vries WB, Bakker JM, Kavelaars A, van Dijk JE, Schipper ME, et al. Reduced life expectancy in rats after neonatal dexamethasone treatment. Pediatr Res (2007) 61(1):72-6. doi:10.1203/01.pdr.0000249980.95264.dd

95. Kamphuis PJ, Bakker JM, Broekhoven MH, Kunne C, Croiset G, Lentjes EG, et al. Enhanced glucocorticoid feedback inhibition of hypothalamo-pituitaryadrenal responses to stress in adult rats neonatally treated with dexamethasone. Neuroendocrinology (2002) 76(3):158-69. doi:10.1159/000064526

96. Kamphuis PJ, Gardoni F, Kamal A, Croiset G, Bakker JM, Cattabeni F, et al. Long-lasting effects of neonatal dexamethasone treatment on spatial learning and hippocampal synaptic plasticity: involvement of the NMDA receptor complex. FASEB J (2003) 17(8):911-3. doi:10.1096/fj.02-0333fje

97. Claessens SE, Belanoff JK, Kanatsou S, Lucassen PJ, Champagne DL, de Kloet ER. Acute effects of neonatal dexamethasone treatment on proliferation and astrocyte immunoreactivity in hippocampus and corpus callosum: towards a rescue strategy. Brain Res (2012) 1482:1-12. doi:10.1016/j.brainres. 2012.08.017

98. Bohn MC, Lauder JM. Cerebellar granule cell genesis in the hydrocortisonetreated rats. Dev Neurosci (1980) 3(2):81-9. doi:10.1159/000112380

99. Claessens SEF. Programming the Brain: Towards intervention strategies. Ph.D. thesis, Leiden University, Leiden (2012).

100. Champagne DL, Bagot RC, van Hasselt F, Ramakers G, Meaney MJ, de Kloet ER, et al. Maternal care and hippocampal plasticity: evidence for experiencedependent structural plasticity, altered synaptic functioning, and differential responsiveness to glucocorticoids and stress. J Neurosci (2008) 28(23):6037-45. doi:10.1523/JNEUROSCI.0526-08.2008

101. Barker DJ. Fetal growth and adult disease. Br J Obstet Gynaecol (1992) 99(4):275-6. doi:10.1111/j.1471-0528.1992.tb13719.x

102. de Kloet ER, Sibug RM, Helmerhorst FM, Schmidt MV. Stress, genes and the mechanism of programming the brain for later life. Neurosci Biobehav Rev (2005) 29(2):271-81. doi:10.1016/j.neubiorev.2004.10.008

103. Sibug RM, de Koning J, Tijssen AM, de Ruiter MC, de Kloet ER, Helmerhorst FM. Urinary gonadotrophins but not recombinant gonadotrophins reduce expression of VEGF120 and its receptors flt-1 and flk-1 in the mouse uterus during the peri-implantation period. Hum Reprod (2005) 20(3):649-56. doi:10.1093/humrep/deh648

104. Sibug RM, Datson N, Tijssen AM, Morsink M, de Koning J, de Kloet ER, et al. Effects of urinary and recombinant gonadotrophins on gene expression profiles during the murine peri-implantation period. Hum Reprod (2007) 22(1):75-82. doi:10.1093/humrep/del363

105. Daskalakis NP, Oitzl MS, Schächinger H, Champagne DL, de Kloet ER. Testing the cumulative stress and mismatch hypotheses of psychopathology in a rat model of early-life adversity. Physiol Behav (2012) 106(5):707-21. doi:10.1016/j.physbeh.2012.01.015

106. Daskalakis NP, Bagot RC, Parker KJ, Vinkers CH, de Kloet ER. The three-hit concept of vulnerability and resilience: toward understanding adaptation to early-life adversity outcome. Psychoneuroendocrinology (2013) 38(9):1858-73. doi:10.1016/j.psyneuen.2013.06.008

107. Gluckman PD, Hanson MA. Developmental plasticity and human disease: research directions. J Intern Med (2007) 261(5):461-71. doi:10.1111/j.13652796.2007.01802.x

108. Nederhof E, Schmidt MV. Mismatch or cumulative stress: toward an integrated hypothesis of programming effects. Physiol Behav (2012) 106:691-700. doi:10.1016/j.physbeh.2011.12.008

109. Champagne DL, de Kloet ER, Joëls M. Fundamental aspects of the impact of glucocorticoids on the (immature) brain. Semin Fetal Neonatal Med (2009) 14(3):136-42. doi:10.1016/j.siny.2008.11.006

110. Oitzl MS, Champagne DL, van der Veen R, de Kloet ER. Brain development under stress: hypotheses of glucocorticoid actions revisited. Neurosci Biobehav Rev (2010) 34(6):853-66. doi:10.1016/j.neubiorev.2009.07.006

111. Claessens SE, Daskalakis NP, van der Veen R, Oitzl MS, de Kloet ER, Champagne DL. Development of individual differences in stress responsiveness: an overview of factors mediating the outcome of early life experiences. Psychopharmacology (Berl) (2011) 214:141-54. doi:10.1007/s00213-010-2118-y

112. Bagot RC, van Hasselt FN, Champagne DL, Meaney MJ, Krugers HJ, Joëls M. Maternal care determines rapid effects of stress mediators on synaptic plasticity in adult rat hippocampal dentate gyrus. Neurobiol Learn Mem (2009) 92(3):292-300. doi:10.1016/j.nlm.2009.03.004

113. Bagot RC, Tse YC, Nguyen HB, Wong AS, Meaney MJ, Wong TP. Maternal care influences hippocampal N-methyl-D-aspartate receptor function and dynamic regulation by corticosterone in adulthood. Biol Psychiatry (2012) 72(6):491-8. doi:10.1016/j.biopsych.2012.03.016

114. Hoffmann A, Spengler D. DNA memories of early social life. Neuroscience (2014) 264:64-75. doi:10.1016/j.neuroscience.2012.04.003

115. Peña CJ, Bagot RC, Labonté B, Nestler EJ. Epigenetic signaling in psychiatric disorders. J Mol Biol (2014). doi:10.1016/j.jmb.2014.03.016

116. Suderman M, McGowan PO, Sasaki A, Huang TC, Hallett MT, Meaney MJ, et al. Conserved epigenetic sensitivity to early life experience in the rat and human hippocampus. Proc Natl Acad Sci U S A (2012) 109(2):17266-72. doi:10.1073/pnas.1121260109

117. Murgatroyd C, Patchev AV, Wu Y, Micale V, Bockmühl Y, Fischer D, et al. Dynamic DNA methylation programs persistent adverse effects of early-life stress. Nat Neurosci (2009) 12(12):1559-66. doi:10.1038/nn.2436

118. Wyrwoll CS, Holmes MC. Prenatal excess glucocorticoid exposure and adult affective disorder: a role of serotonergic and catecholamine pathways. Neuroendocrinology (2012) 95:47-55. doi:10.1159/000331345

119. McGowan PO, Sasaki A, D’Alessio AC, Dymov S, Labonté B, Szyf M, et al. Epigenetic regulation of the glucocorticoid receptor in human brain associates with childhood abuse. Nat Neurosci (2009) 12(3):342-8. doi:10.1038/nn. 2270

120. Weaver IC, Meaney MJ, Szyf M. Maternal care effects on the hippocampal transcriptome and anxiety-mediated behaviors in the offspring that are reversible in adulthood. Proc Natl Acad Sci U S A (2006) 103(9):3480-5. doi:10.1073/pnas.0507526103

121. Polman JA, Hunter RG, Speksnijder N, van den Oever JME, Korobko OB, McEwen BS, et al. Glucocorticoids modulate the mTOR pathway in the hippocampus: differential effects depending on stress history. Endocrinology (2012) 153(3):4317-27. doi:10.1210/en.2012-1255

122. Datson NA, van den Oever JM, Korobko OB, Magarinos AM, de Kloet ER, McEwen BS. Previous history of chronic stress changes the transcriptional response to glucocorticoid challenge in the dentate gyrus region of the male rat hippocampus. Endocrinology (2013) 154(9):3261-72. doi:10.1210/en.20122233

123. Gray JD, Rubin TG, Hunter RG, McEwen BS. Hippocampal gene expression changes underlying stress sensitization and recovery. Mol Psychiatry (2013). doi:10.1038/mp.2013.175 
de Kloet et al.

Perinatal glucocorticoid action

124. Crude A, Petropoulos S, Moisiadis VG, Iqbal M, Kostaki A, Machines Z, et al. Prenatal synthetic glucocorticoid treatment changes DNA methylation states in male organ systems: multigenerational effects. Endocrinology (2012) 153(7):3269-83. doi:10.1210/en.2011-2160

125. Crude A, Suderman M, Moisiadis VG, Petropolous S, Kostaki A, Mallet M, et al. Glucocorticoid programming of the fetal male hippocampal epigenome. Endocrinology (2013) 154(3):1168-80. doi:10.1210/en.2012-1980

126. Crude A, Petropoulos S, Suderman M, Moisiadis VG, Kostaki A, Mallet M, et al. Effects of antenatal synthetic glucocorticoid on glucocorticoid receptor binding, DNA methylation, and genome-wide mRA levels in the fetal male hippocampus. Endocrinology (2013) 154(11):4170-81. doi:10.1210/en.2013-1484

127. Dolman JA, de Kloet ER, Datson NA. Two populations of glucocorticoid receptor-binding sites in the male rat hippocampal genome. Endocrinology (2013) 154(5):1832-44. doi:10.1210/en.2012-2187

128. Brownfoot FC, Gagliardi DI, Brain E, Middleton P, Crowther CA. Different corticosteroids and regimens for accelerating fetal lung maturation for women at risk of preterm birth. Cochrane Database Syst Rev (2013) 8:CD006764. doi:10.1002/14651858.CD006764.pub3

129. Kersbergen KJ, de Vries LS, van Kooij BJ, Išgum I, Rademaker KJ, van Bel F, et al. Hydrocortisone treatment for bronchopulmonary dysplasia and brain volumes in preterm infants. J Pediatr (2013) 163(3):666.e-71.e. doi:10.1016/j. jpeds.2013.04.001

130. Hawser J, Feldon J, Pryce CR. Direct and dam-mediated effects of prenatal dexamethasone on emotionality, cognition and HPA axis in adult Wistar rats. Hort Behave (2009) 56(4):364-75. doi:10.1016/j.yhbeh.2009.07.003

131. Morley-Fletcher S, Kea M, Maccari S, Laviola G. Environmental enrichment during adolescence reverses the effects of prenatal stress on play behavejour and HPA axis reactivity in rats. Eur J Neurosci (2003) 18:3367-74. doi:10.1111/j.1460-9568.2003.03070.x
132. Field T, Diego M, Hernandez-Reif M. Preterm infant massage therapy research: a review. Infant Behav Lev (2010) 33(2):115-24. doi:10.1016/j.infbeh.2009.12. 004

133. Middlemiss W, Granger DA, Goldberg WA, Nathans L. Asynchrony of motherinfant hypothalamic-pituitary-adrenal axis activity following extinction of infant crying responses induced during the transition to sleep. Early Hum Nev (2012) 88(4):227-32. doi:10.1016/j.earlhumdev.2011.08.010

134. Lewis AJ, Galbally M, Gannon T, Symeonides C. Early life programming as a target for prevention of child and adolescent mental disorders. BMC Med (2014) 12:33. doi:10.1186/1741-7015-12-33

Conflict of Interest Statement: E. Ronald de Kloet is on the Scientific Advisory Board and owns stock of Concept Therapeutics, and also served on the Advisory Boards of Dynacorts Therapeutics and Pharmaseed Ltd. The other co-authors report no conflicts of interest.

Received: 25 April 2014; accepted: 11 June 2014; published online: 09 July 2014.

Citation: de Kloet ER, Claessens SEF and Kentrop J (2014) Context modulates outcome of perinatal glucocorticoid action in the brain. Front. Endocrinol. 5:100. do: 10.3389/fendo.2014.00100

This article was submitted to Neuroendocrine Science, a section of the journal Frontiers in Endocrinology.

Copyright (๑) 2014 de Kloet, Claessens and Kentrop. This is an open-access article distribute under the terms of the Creative Commons Attribution License (CC BY). The use, distribution or reproduction in other forums is permitted, provided the original author (s) or licenser are credited and that the original publication in this journal is cited, in accordance with accepted academic practice. No use, distribution or reproduction is permitted which does not comply with these terms.

www.frontiersin.org

July 2014 | Volume 5 | Article 100 | 13 